GLOBAL BIOGEOCHEMICAL CYCLES, VOL. 5, NO. 1, PAGES 71-85, MARCH 1991

\section{DISSOLVED ORGANIC CARBON IN MODELING OCEANIC NEW PRODUCTION}

\author{
R. Bacastow \\ Scripps Institution of Oceanography \\ La Jolla, California \\ E. Maier-Reimer \\ Max-Planck-Institut für Meteorologie \\ Hamburg, Germany
}

it not for this transport, the surface dissolved inorganic carbon (DIC) concentration would be larger, and the atmospheric $\mathrm{CO}_{2}$ concentration would be much larger. Understanding the mechanisms of this transport is important if we are to predict the effect of change in climate and resulting change in ocean circulation upon the atmospheric $\mathrm{CO}_{2}$ level.

Until recently, it was generally thought that the flux of new production was carried almost entirely by vertically falling particulate organic carbon (POC). However, measurements of oceanic dissolved organic carbon (DOC) by a new technique [Sugimura and Suzuki, 1988] has revealed an active pool that is several times larger than indicated by previous measurements. The new measurements of DOC concentration show variations with depth which correlate with dissolved nitrate and oxygen concentrations, suggestive that DOC is actively involved in the carbon cycle, whereas older DOC measured concentrations show little change with depth. Toggweiler [1988a,b], Williams and Druffel [1988], and Jackson [1988] have all discussed these measurements and their oceanographic implications. The new measurements of DOC are still controversial, but preliminary confirmation has been reported (P. M. Williams, personal communication, 1990; E. T. Peltzer, personal communication, 1990).

Here we wish to compare models of oceanic chemical distributions, both with and without the assumption of an active pool of DOC, with oceanographic data. Is it possible to get reasonable agreement with POC only, considering uncertainties in the models, and if not, in what way do the models then differ from the data? How much better is agreement if transport of new production by DOC is also included? (A preliminary version of this work has been submitted for publication in a volume of papers presented at a conference sponsored by the Electric Power Research Institute at Lake Arrowhead,

Paper number 91GB00015. 0886-6236/91/91GB-00015 $\$ 10.00$ 
October, 1988.) We employ an oceanic carbon cycle model that is three dimensional and based on an oceanic general circulation model (GCM) developed at the Max Planck Institute for Meteorology, Hamburg, Germany [Maier-Reimer and Hasselmann, 1987; Bacastow and Maier-Reimer, 1990|. This type of model is particularly appropriate for the questions posed above because advection of DOC has three-dimensional consequences.

Toggweiler et al. [1988b] and Sarmiento et al. [1988] have described the effect of transport of the new production flux by DOC, in addition to POC, in a three-dimensional, flat bottomed sector model of a single ocean basin. Their chemical model included only the nutrient phosphate. The predicted phosphate concentration was adjusted to be close to the observed concentration, and the required adjustment was then attributed to new production. They found that with transport only by POC, subsurface values of phosphate in upwelling regions were much too large. We use a model with realistic geometry, within the limitations of the grid, and include in our chemical model, in addition to phosphate, dissolved inorganic carbon (DIC), alkalinity, and oxygen. We model new production directly, and "spin-up" the model until unchanging, equilibrium concentrations result. About 1800 model years is required, which takes 23 minutes of Cray Y-MP time. This time is short enough that the effect of variation of parameters in the model can be studied.

\section{NEW PRODUCTION}

New production has been defined by Dugdale and Goering [1967] to be that portion of primary production which incorporates nitrogen from the uptake of dissolved nitrate. It can be measured by isotope techniques. Destruction of soft tissue ordinarily releases reduced forms of nitrogen, such as ammonia and urea, which phytoplankton prefer to the more oxidized nitrite and nitrate. In surface water, reduced nitrogen is quickly converted to organic matter through photosynthesis, but in deep water it becomes oxidized to nitrate before being returned to the surface. Consequently, at steady state, new production as defined by Dugdale and Goering must equal the portion of primary production that is transported to deeper water.

\section{NEWLY DISCOVERED DOC}

Ocean water apparently contains a large pool of DOC that has not been previously recognized. Ocean chemists in Japan, with a new method of analysis, have reported finding much more DOC and dissolved organic nitrogen (DON) in the ocean than was previously found [Suzuki et al., 1985; Sugimura and Suzuki, 1988]. They use a high-temperature catalytic oxidation method; older methods are based on oxidation by ultraviolet light, persulfuric acid, and other "wet" oxidizing agents. In near-surface water, the difference between the new measurements and older measurements is several times the amount found through the older methods.
The additional DOC measured by the new analysis method has been found to be of higher molecular weight than the DOC detected by the older methods [Sugimura and Suzuki, 1988] and must be more resistant to ultraviolet and wet oxidation techniques but nevertheless more readily consumed in surface waters, possibly by marine microbes. It must have a lifetime that is short compared with the time water resides in the thermocline because mostly it is confined to the upper $400-500 \mathrm{~m}$. The DOC found by older methods is only a little higher in concentration in surface water and shows little structure in deeper water, so it must be resistant to consumption by marine microbes. Its ${ }^{14} \mathrm{C}$ age is about 1300 years in surface water and about 6000 years in deep water [Williams and Druffel, 1987]. Consequently, the DOC found by older methods cannot be important for the transport of organic carbon and associated nutrients in the ocean.

We are thus led to the simplified picture (Figure 1) where there are two DOC pools, "old" DOC, which is inactive, long-lived, and probably not important to the transport of organic carbon, and "new" DOC, a pool of about $150-200 \mu \mathrm{mol} \mathrm{kg}{ }^{-1}$ at the surface that penetrates into the ocean only about $500 \mathrm{~m}$. We have included only the new DOC pool in the carbon cycle model.

Constant Redfield ratios of $\mathrm{O}_{2}: \mathrm{C}: \mathrm{N}: \mathrm{P}=135: 105: 15: 1$ have been assumed to hold for both POC and new DOC. The new DON measurements [Sugimura and Suzuki, 1988] are roughly consistent with this nitrogen Redfield ratio and the size of the new DOC pool discussed above. These DON measurements have not yet been confirmed, but preliminary confirmation of the DOC measurements is supportive. Corresponding measurements of dissolved organic phosphate (DOP) have not yet been reported, but are eagerly awaited.

\section{CARBON CYCLE MODEL}

The carbon cycle model is as described by Bacastow and Maier-Reimer [1990] (hereinafter referred to as BMR), except for a few changes, which will be listed below. Chemical species important to the carbon cycle are advected by the current field of the oceanic GCM. The ocean is represented by 27443 boxes arranged in 10 levels. Mixing occurs through numerical diffusivity (related to finite box size), a very small explicit horizontal diffusivity, and a convective adjustment. An atmospheric box exchanges $\mathrm{CO}_{2}$ with the surface ocean boxes. There is no land biota provided in this version of the model. The oceanic GCM is seasonal, but the carbon cycle model is nonseasonal and employs a seasonally averaged ocean circulation. All photosynthesis is limited to the surface boxes, $\mathbf{1 1 2 . 5}$ m deep. Dissolved oxygen surface concentrations are set to $3 \%$ supersaturation.

New production, PRODC $\mu \mathrm{mol} \mathrm{kg}{ }^{-1} \mathrm{yr}^{-1}$ of $\mathrm{C}$ in surface boxes (or equivalently, $\mathrm{g} \mathrm{C} \mathrm{m}^{-2} \mathrm{yr}^{-1}$ ), is determined by a Michaelis-Menton kinetics equation [Dugdale, 1987], dependent on nutrient concentration, represented by the phosphate concentration, PO4, multiplied by a latitudinally varying incident light factor, LC: 


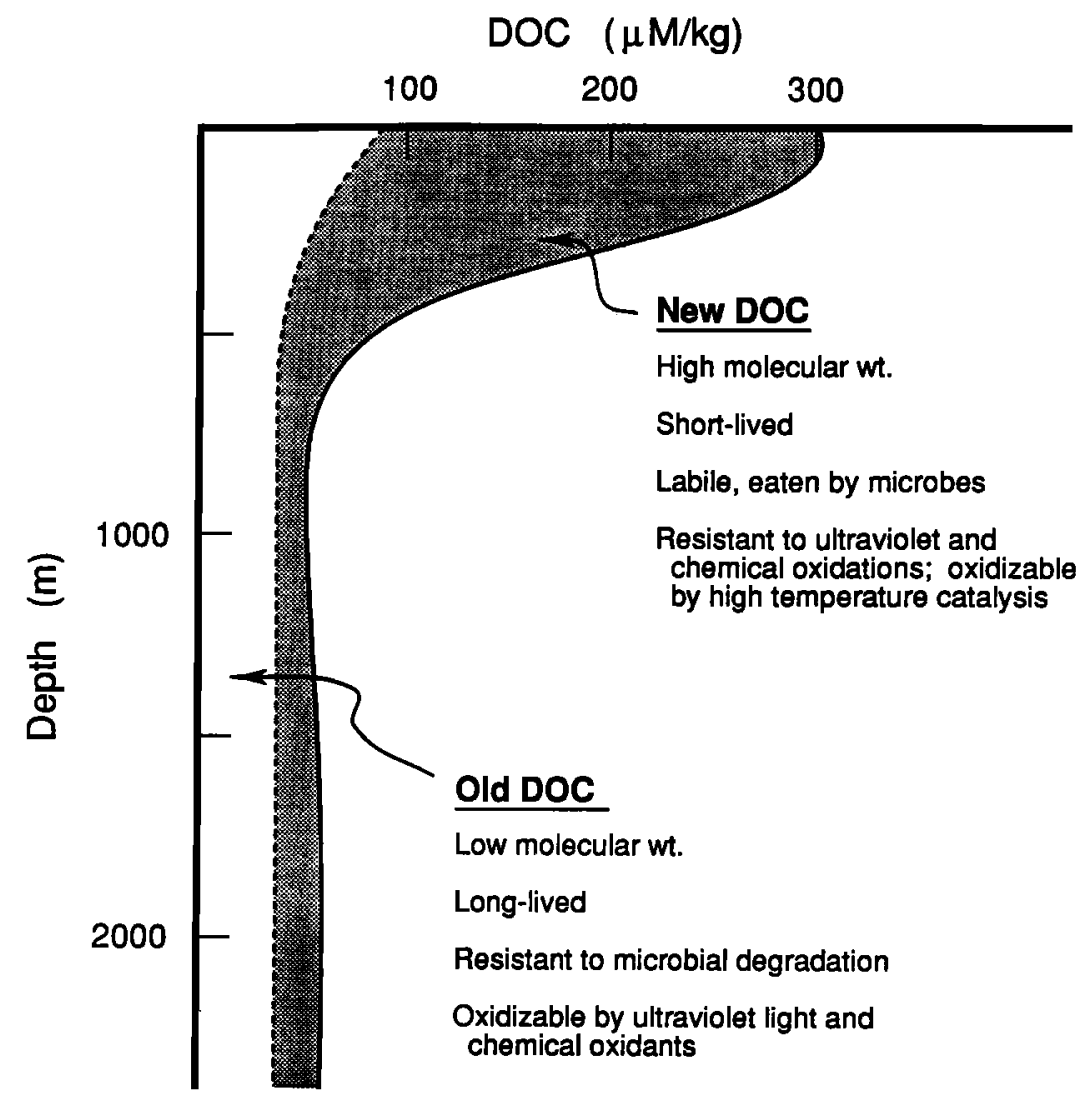

Fig. 1. Illustration of DOC profile indicating "new" DOC, additional DOC found by a new method [Sugimura and Suzuki, 1988], and "old" DOC, that found by older methods.

PRODC $=\mathrm{LC} \cdot \frac{\mathrm{R} \cdot \mathrm{RC} \cdot \mathrm{PO4}}{\mathrm{H}+\mathrm{RC} \cdot \mathrm{PO4}}$

Above, RC is the carbon to phosphate Redfield ratio and $R$ and $H$ are adjustable parameters ( $H$ was fixed at $40 \mu \mathrm{mol} \mathrm{kg}^{-1}$ and $R$ was adjusted as discussed below).

Differences relative to BMR are that (1) the atmospheric exchange time, $\tau_{a m}$, was set to 7.87 years instead of 8 years and (2) DIC in the model was adjusted so that the preindustrial atmospheric concentration of carbon in the model is close to $280 \mathrm{ppm}$ instead of $290 \mathrm{ppm}$. These changes have little effect on the oceanic chemical distributions. The convective adjustment was done once per year, following BMR. Remineralization of vertically falling POC is specified by prescribing an exponential "penetration depth" which was varied between $300 \mathrm{~m}$ and $500 \mathrm{~m}$ instead of being set to $700 \mathrm{~m}$, following BMR. This penetration depth is measured from the bottom of the surface layer.

\section{MODEL WITH POC ONLY}

We find that with new production carried by POC only, we cannot get results that are close to the observed phosphate and oxygen distributions. If the intensity of new production (adjusted by parameter $R$ in equation (1)) is set high enough to reproduce an approximation to the observed surface phosphate values, then the deeper water becomes much more depleted in oxygen than is observed. This is illustrated by contour plots for phosphate and oxygen for models $A$ and $B$ (Figures 2-6). Model $A$ is with the remineralization penetration depth set to $300 \mathrm{~m}$, which is close to the sediment trap observations of Martin et al. [1987] in the northeast Pacific Ocean, and model $B$ is with this parameter set to $500 \mathrm{~m}$. The plot of observed surface phosphate concentrations (Figure 2b) is from data assembled by J. Reid, Scripps Institution of Oceanography (personal communication, 1986), and is averaged over the depth of the surface boxes in the model $(112.5 \mathrm{~m})$, so as to be directly comparable to surface contour plots of the model predictions. Figures $3 \mathrm{~b}, 4 \mathrm{~b}, 5 \mathrm{a}$, and $6 \mathrm{a}$ are for Geochemical Ocean Sections Study (GEOSECS) phosphate and oxygen sections in the eastern and western Pacific Ocean. In these plots, the data have been averaged over the depth resolution of the model. The model plots follow, approximately, the GEOSECS section lines, so again they are directly comparable to the data plots. 


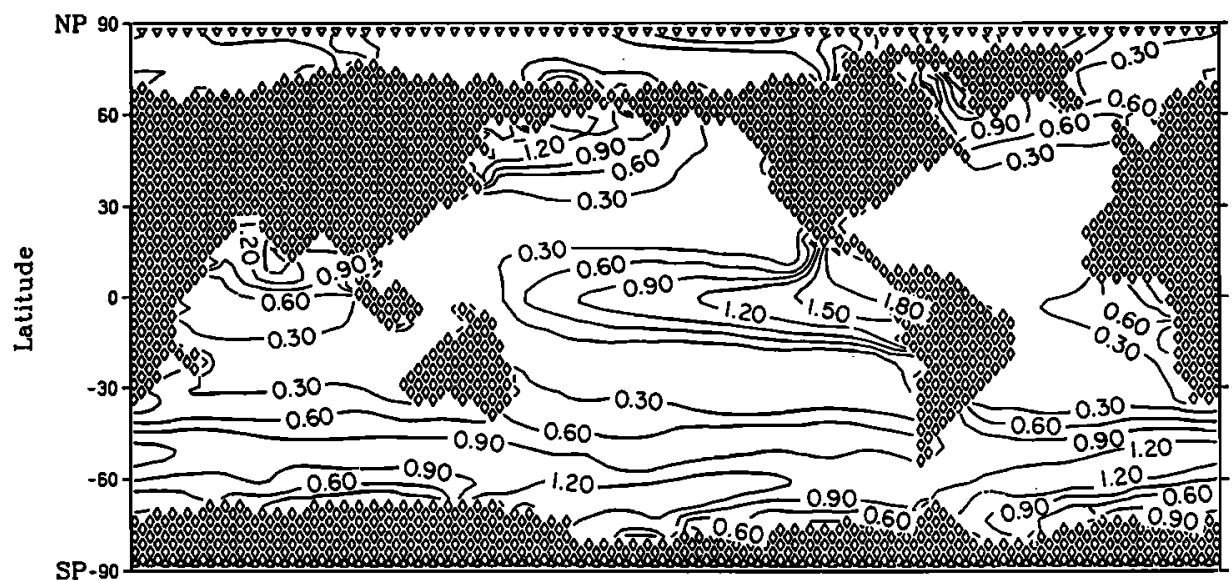

a

Longitude
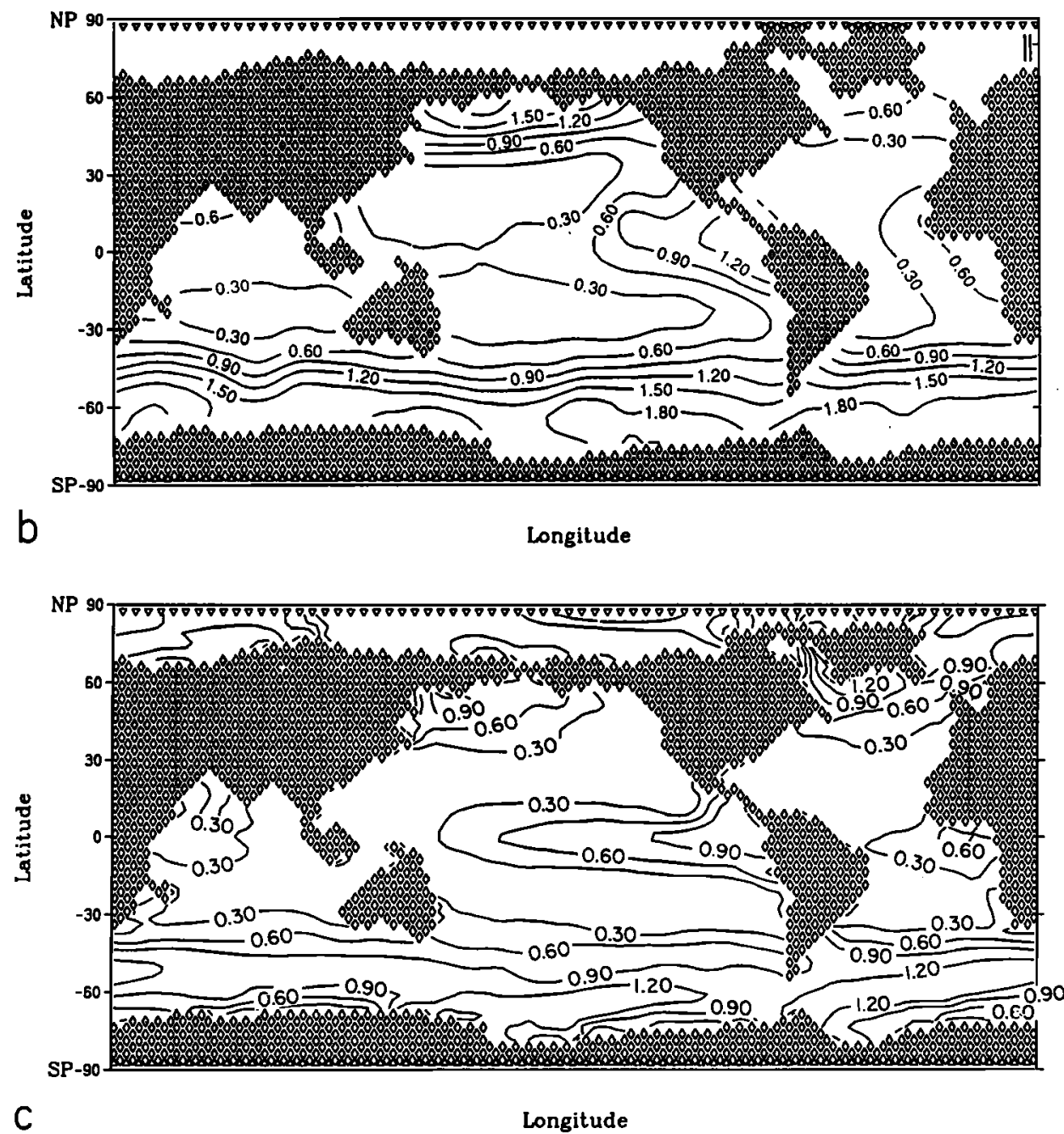

Fig. 2. Surface ocean distributions of inorganic phosphate $\left(\mu \mathrm{mol} \mathrm{kg}^{-1}\right)$ : (a) prediction of model A, (b) observations averaged over the surface $112.5 \mathrm{~m}$ depth so as to correspond to the model surface boxes (from data assembled by J. Reid), and (c) prediction of model C. 


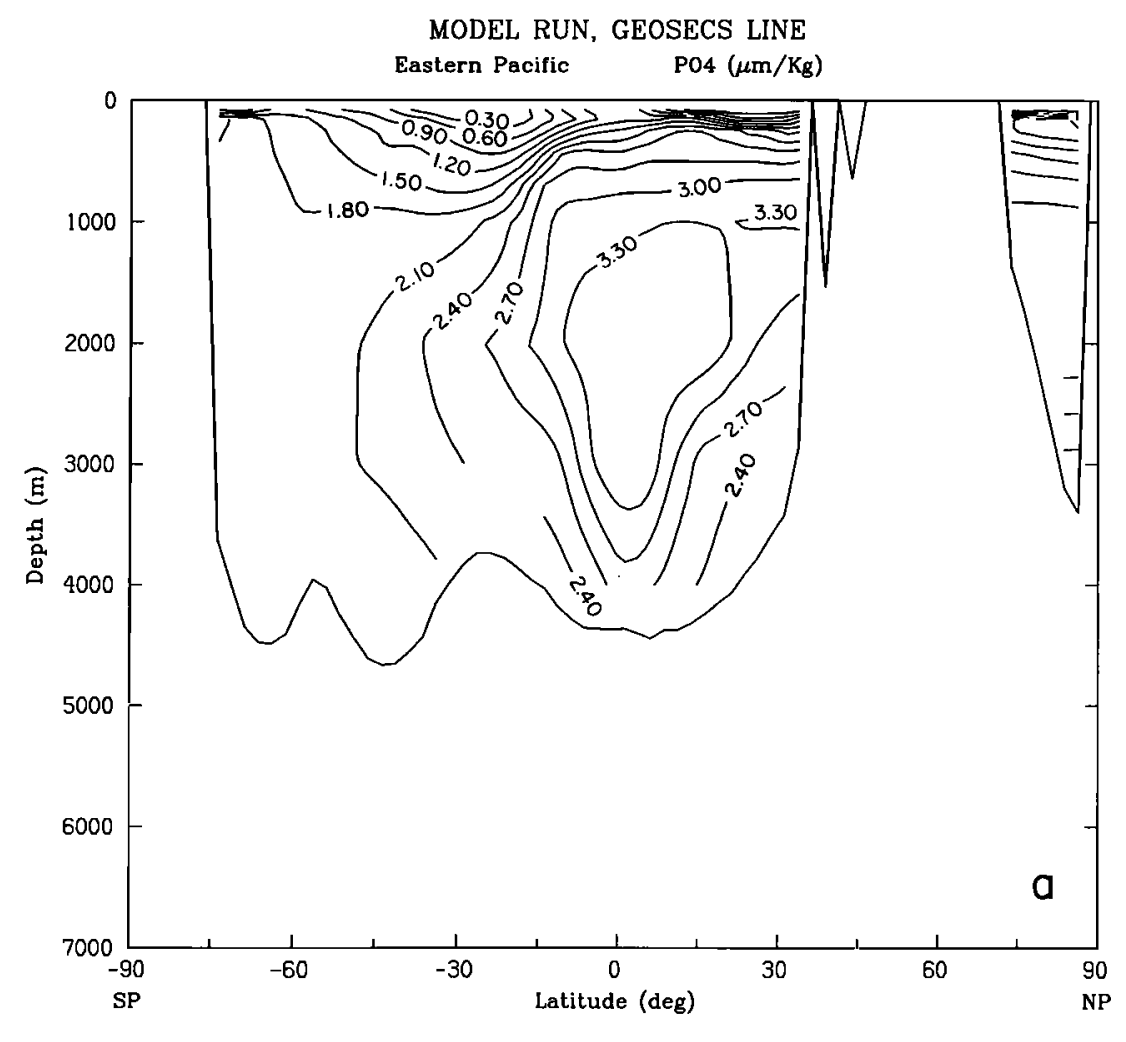

GEOSECS DATA

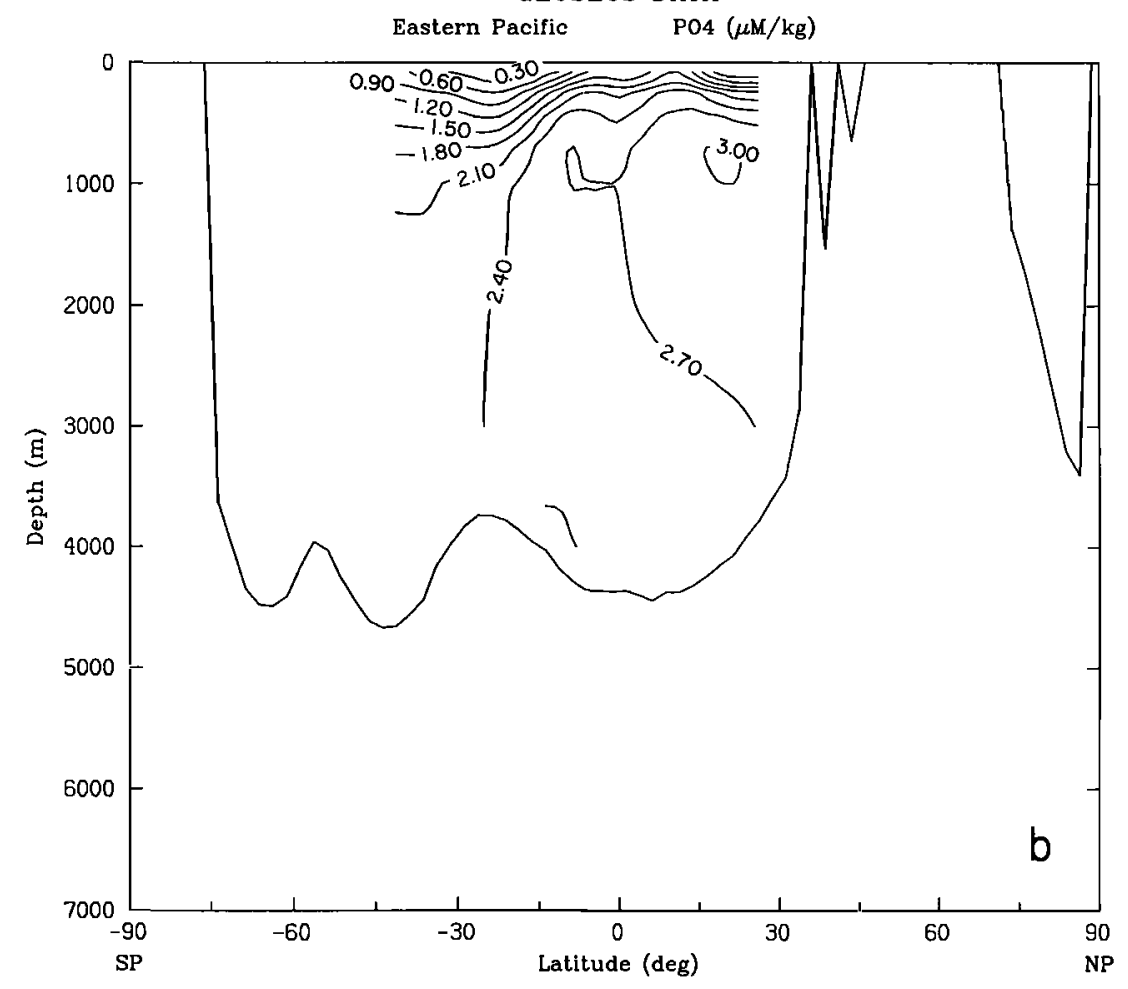

Fig. 3. Vertical sections of inorganic phosphate $\left(\mu \mathrm{mol} \mathrm{kg}{ }^{-1}\right)$ in the eastern Pacific Ocean: (a) prediction of model A, (b) GEOSECS data averaged over the resolution of the model, and (c) prediction of model $\mathbf{C}$. 


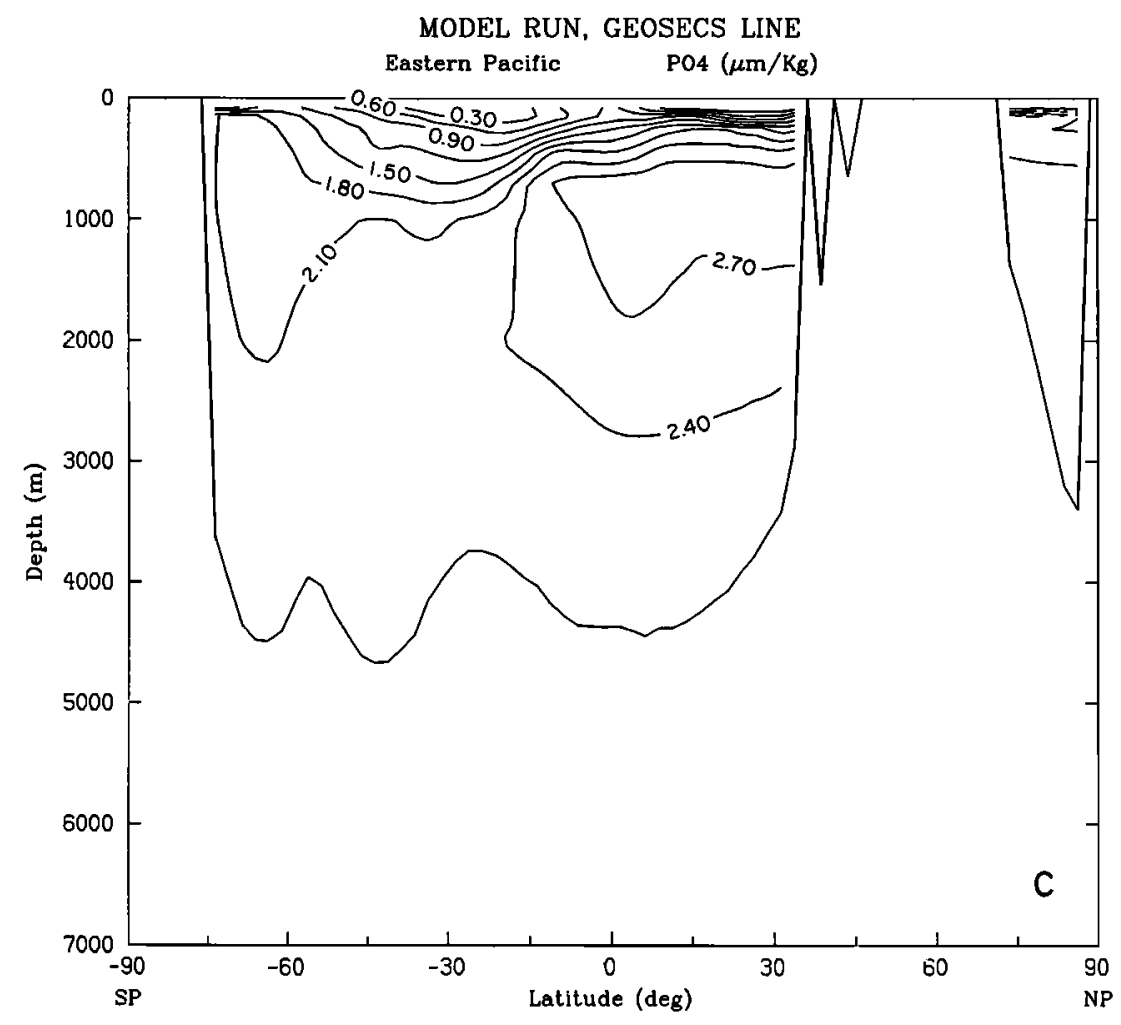

Fig. 3. (continued)

Model A predicts a large body of anoxic water in the Pacific Ocean that is not indicated by the GEOSECS sections. The phosphate maxima are also greater than those observed, especially in the equatorial region, but the difference is not as dramatic as for oxygen. The corresponding predictions for model $B$ are even more discrepant, indicating that the deeper penetration of the POC flux does not help. If the new production formulation (equation (1)) were assumed to be more nearly proportional to the phosphate concentration, or some higher power of the phosphate concentration, the agreement would also be worse because then new production would be more concentrated in upwelling regions like the equatorial region. Use of the more recently proposed Redfield ratios of $\mathrm{O}_{2}: \mathrm{C}: \mathrm{N}: \mathrm{P}$ of 177:133:17.5:1 [Takahashi et al., 1985; Peng and Broecker, 1987] would make the oxygen deficiency even larger.

What can one conclude from these results? Lack of agreement between model prediction and observations could be due to either, or both, shortcomings in the circulation field or shortcomings in the modeling of the carbon cycle. One shortcoming in the circulation field that became evident in earlier work [see BMR] is that too much of the deep water formation is in the southern oceans relative to the North Atlantic. Partly for this reason, the Pacific Ocean is better modeled than the Atlantic Ocean. However, we do not think that an improvement in circulation could remove the discrepancies illustrated above. To a first approximation, the upward movement of nutrient from deep water to surface water must be made more difficult, while at the same time, movement of oxygen downward must be made easier. Nevertheless, if we did not know about the pool of more active DOC, our first thought would be that there is a problem with the circulation field. In fact, this is essentially what happened historically in the development of the carbon cycle model described by BMR. To avoid distorting deep water distributions of oxygen, phosphate, and DIC, total new production was adjusted to a value that left surface phosphate concentrations about twice their observed values.

\section{MODEL WITH POC AND DOC}

We postulate that consumption of the new DOC pool can be modeled as a first-order process similar to radioactive decay, with the assignment of a single lifetime. If new DOC were consumed by a population of microbes that was uniformly distributed in the ocean, one would expect the loss in concentration of new DOC to depend on the first power of the concentration of new DOC, and the multiplying constant would be an inverse lifetime. However, even if new DOC is consumed by microbes, the population of these microbes is probably not uniform in the ocean, so the aforementioned postulate must be an approximation, at best. A more elaborate model might 

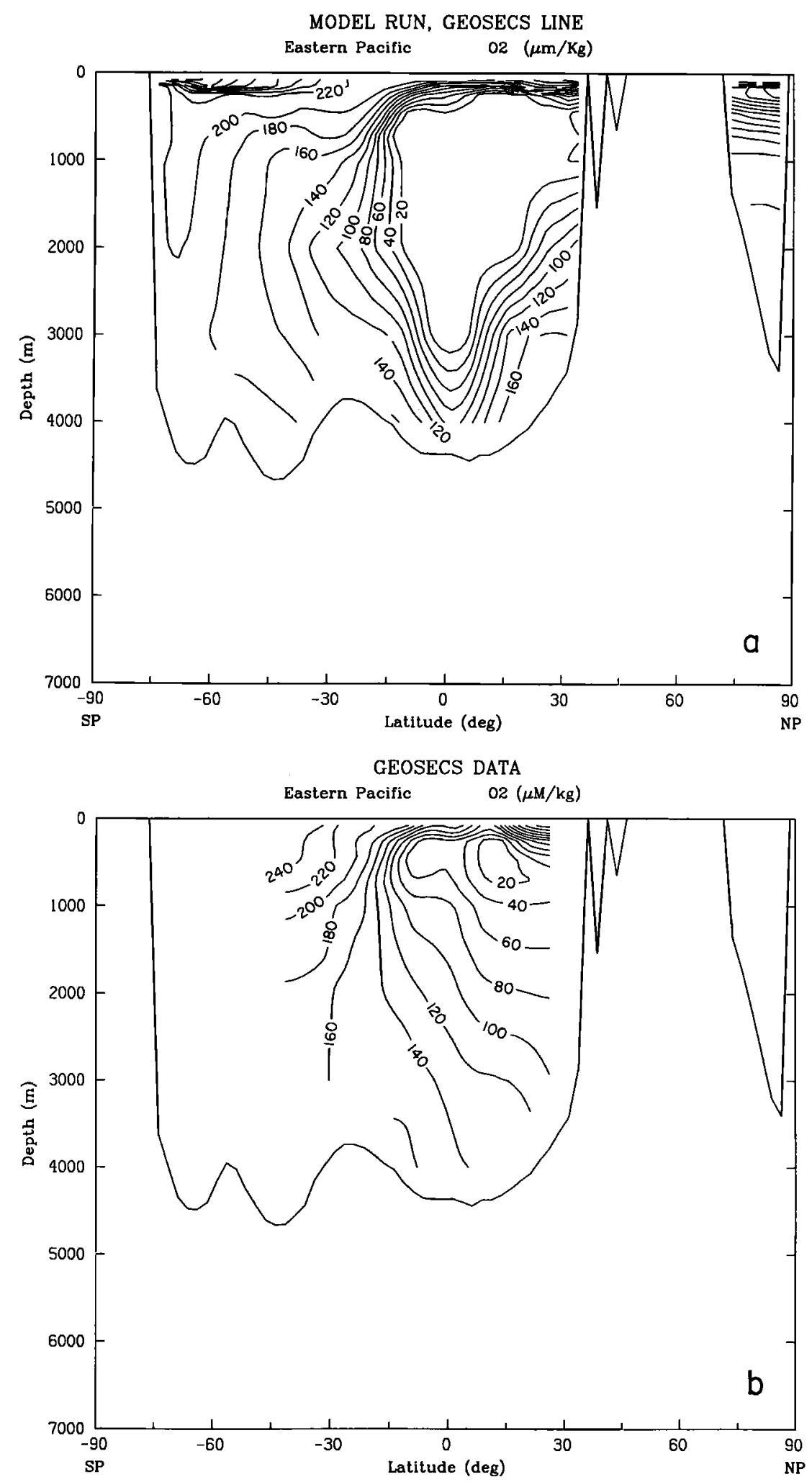

Fig. 4. Vertical sections of dissolved oxygen $\left(\mu \mathrm{mol} \mathrm{kg}{ }^{-1}\right)$ in the eastern Pacific Ocean: (a) prediction of model A, (b) GEOSECS data averaged over the resolution of the model, and (c) prediction of model $\mathrm{C}$. 


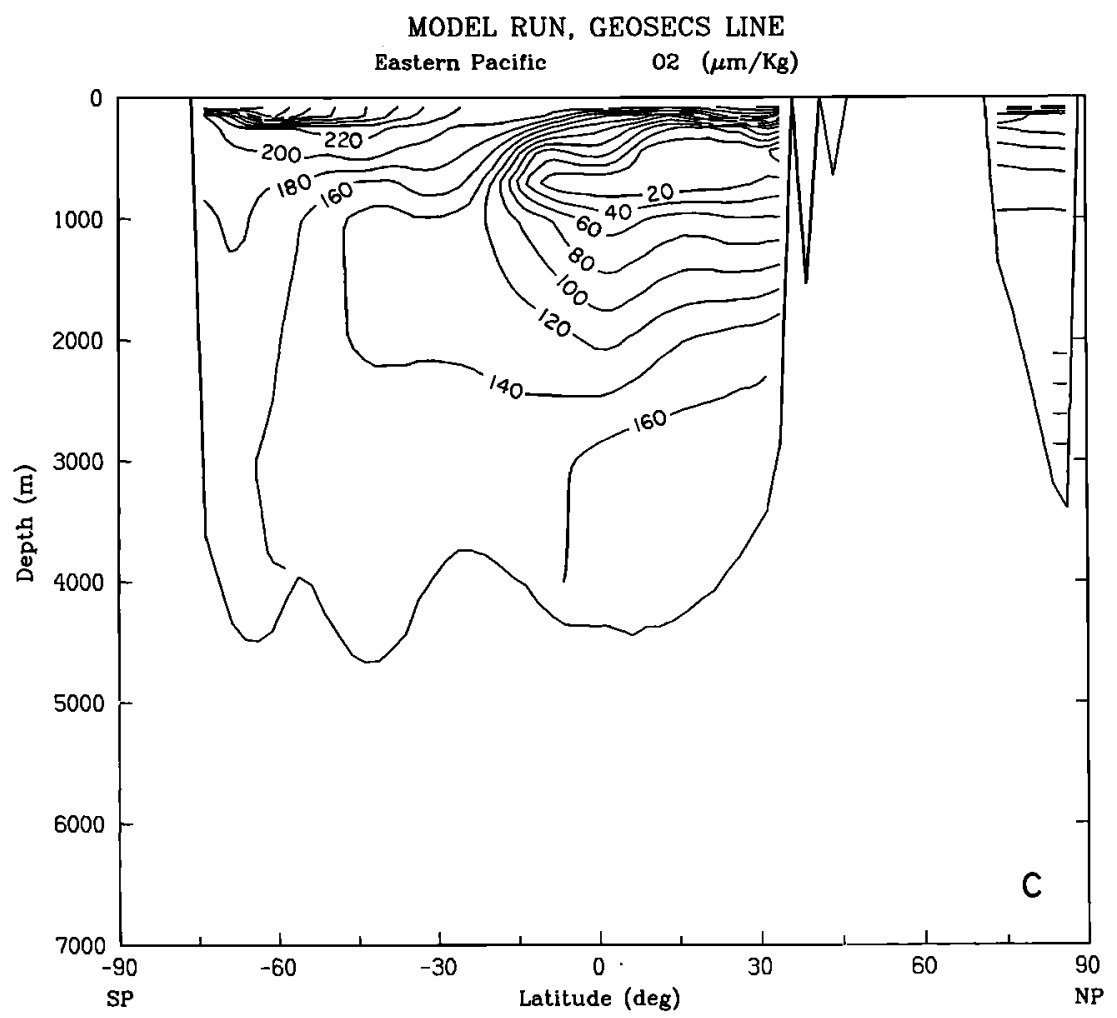

Fig. 4. (continued)

include several pools of DOC with different lifetimes dependent on depth and perhaps also location. The nutrient to carbon ratio associated with each of these pools might also differ. Here, for simplicity, we have assumed that the Redfield ratios in new DOC are the same as in POC and that they are constant everywhere in the ocean. We have also assumed that nutrients released by new DOC that is consumed in the surface boxes of the model are immediately recycled and that nutrients from new DOC consumed in deeper boxes are simply released to solution as phosphate and nitrate.

With the inclusion of transport of the flux of new production by new DOC as well as POC, as in model C (Figures 2c, 3c, 4c, 5d, and 6d), improved agreement between predictions and observations relative to model $A$ is immediately apparent. The large mass of oxygen depleted water in the Pacific Ocean is replaced by water with an oxygen minimum with value, size, and depth that are similar to that observed. The phosphate maximum is also at more nearly the observed value and depth. The improvement is probably the result of horizontal transport of nutrient associated with advection of DOC. Advection carries nutrient much further from the upwelling regions of intense photosynthesis than does falling POC, and the return of the nutrient and its participation in further photosynthesis is thus delayed, giving the biota more time to reduce surface nutrient concentration without producing so much downward flux of organic matter that deeper water oxygen is depleted.

Schematics of the transport of new production between the surface layer and deeper water are shown in Figure 7 for models $A$ and $C$. In model $C$ there are two more parameters than model A: $r$, the lifetime of the new DOC, and $g$, the fraction of "export production" which leaves the formation area as new DOC instead of sinking to below surface water as POC. The term "export production" here refers to that portion of primary production that leaves the formation area, as either POC or newly produced new DOC. At steady state, export production must equal the sum of the new production and the production corresponding to the loss (consumption) of new DOC in surface water. In model A, export production equals new production, but in model $\mathrm{C}$, it is larger.

The value of $\tau$ was set to 50 years so that the new DOC would be mostly consumed within the upper 1000 $m$ of the ocean. Since only a small portion of the new DOC was intended to reach the deep waters, the use of a single lifetime, appropriate for surface water, is thought to be a reasonable approximation. The value of $g$ was adjusted to 0.7 so that the concentration of new DOC in the surface layer would be about $150 \mu \mathrm{mol} \mathrm{kg}{ }^{-1}$. The average concentration of new DOC declines from 151 $\mu \mathrm{mol} \mathrm{kg}-1$ in the surface layer to $60 \mu \mathrm{mol} \mathrm{kg}{ }^{-1}$ at a depth of $400 \mathrm{~m}$ and $13 \mu \mathrm{mol} \mathrm{kg}{ }^{-1}$ at $1000 \mathrm{~m}$. The ocean average new DOC concentration is $20.2 \mu \mathrm{mol} \mathrm{kg}{ }^{-1}$. The 

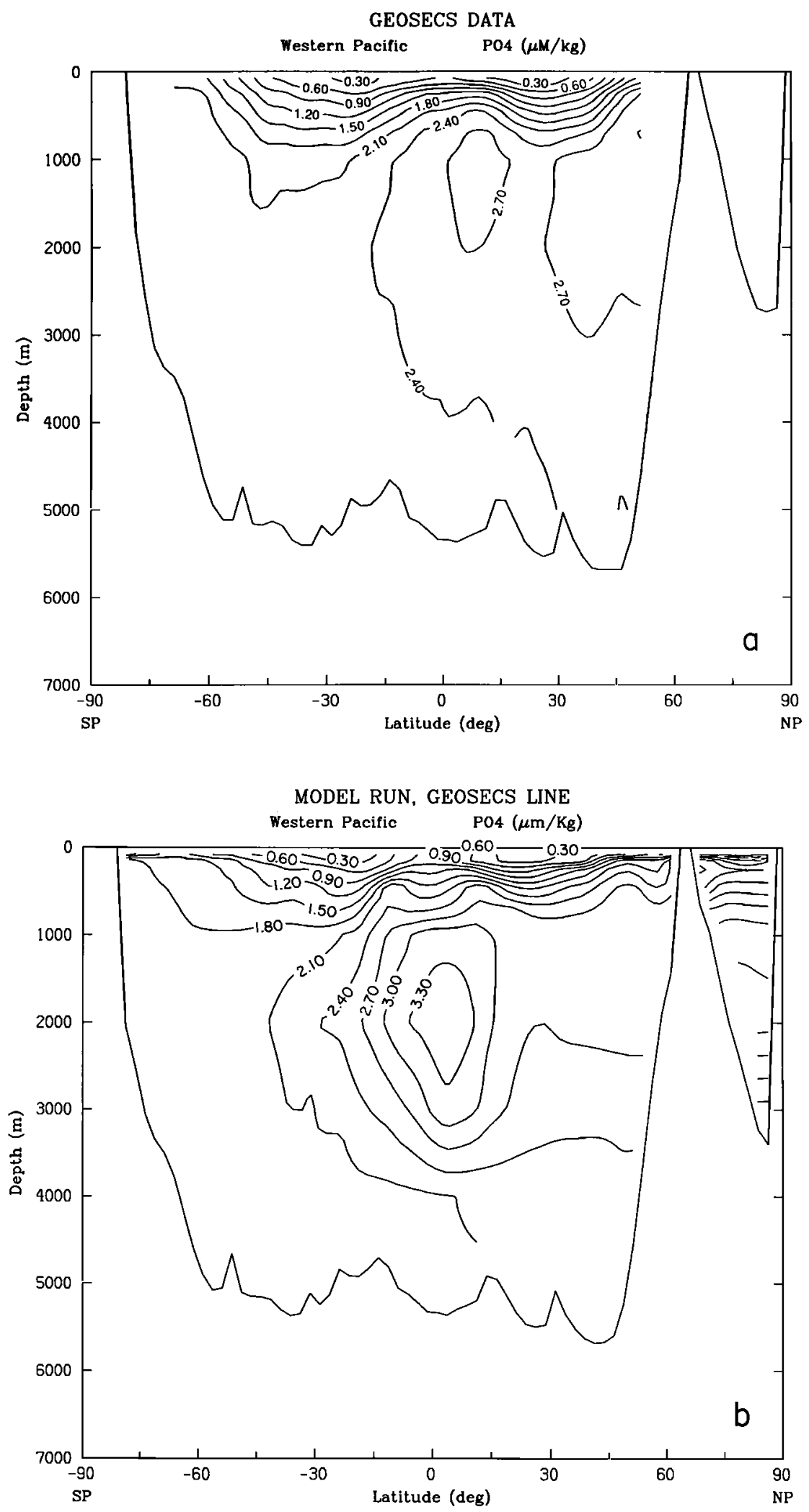

Fig. 5. Vertical sections of inorganic phosphate $\left(\mu \mathrm{mol} \mathrm{kg}^{-1}\right)$ in the western Pacific Ocean: (a) GEOSECS data averaged over the resolution of the model, (b) prediction of model A, (c) prediction of model B, and (d) prediction of model C. 

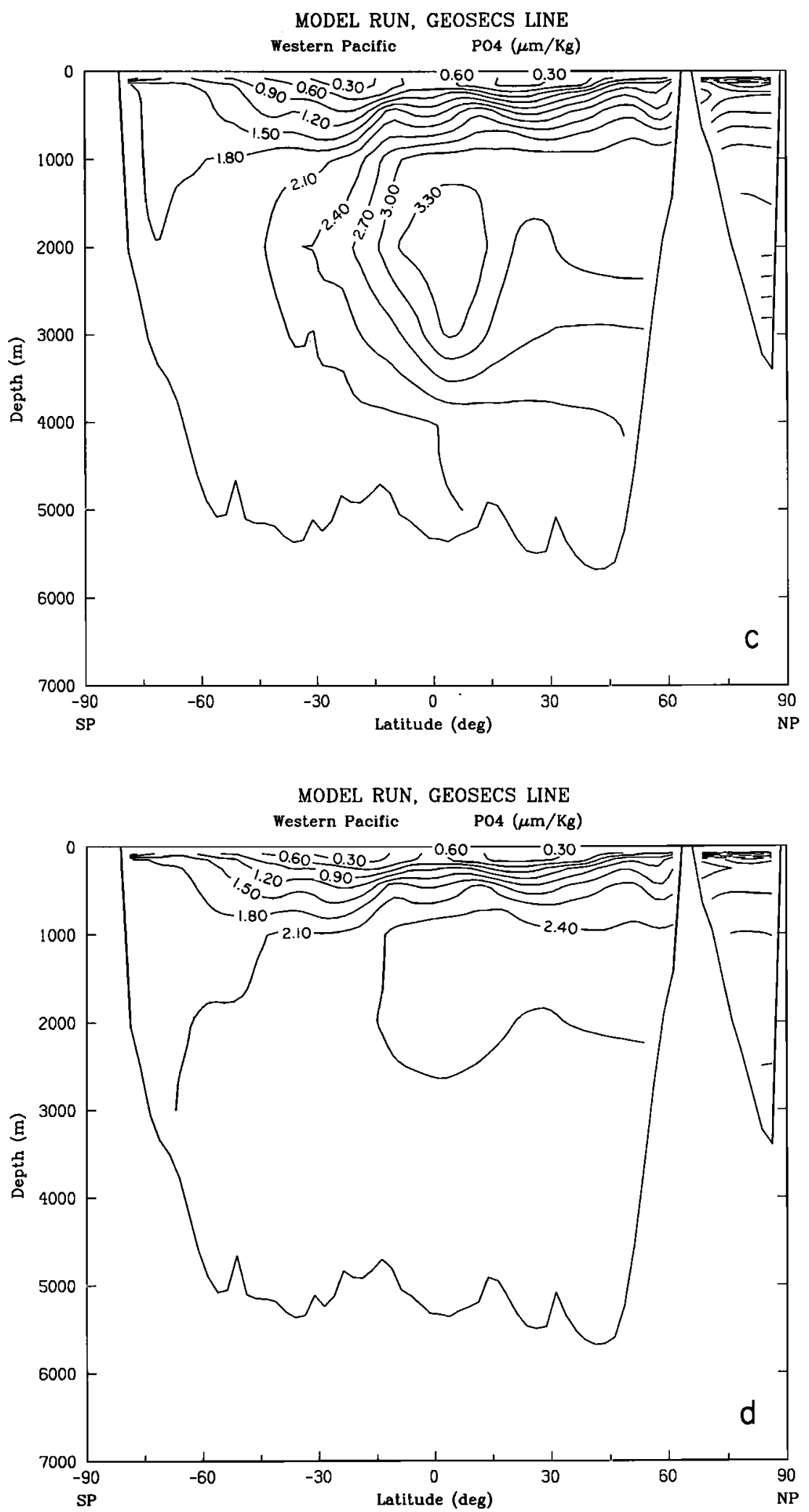

Fig. 5. (continued) 

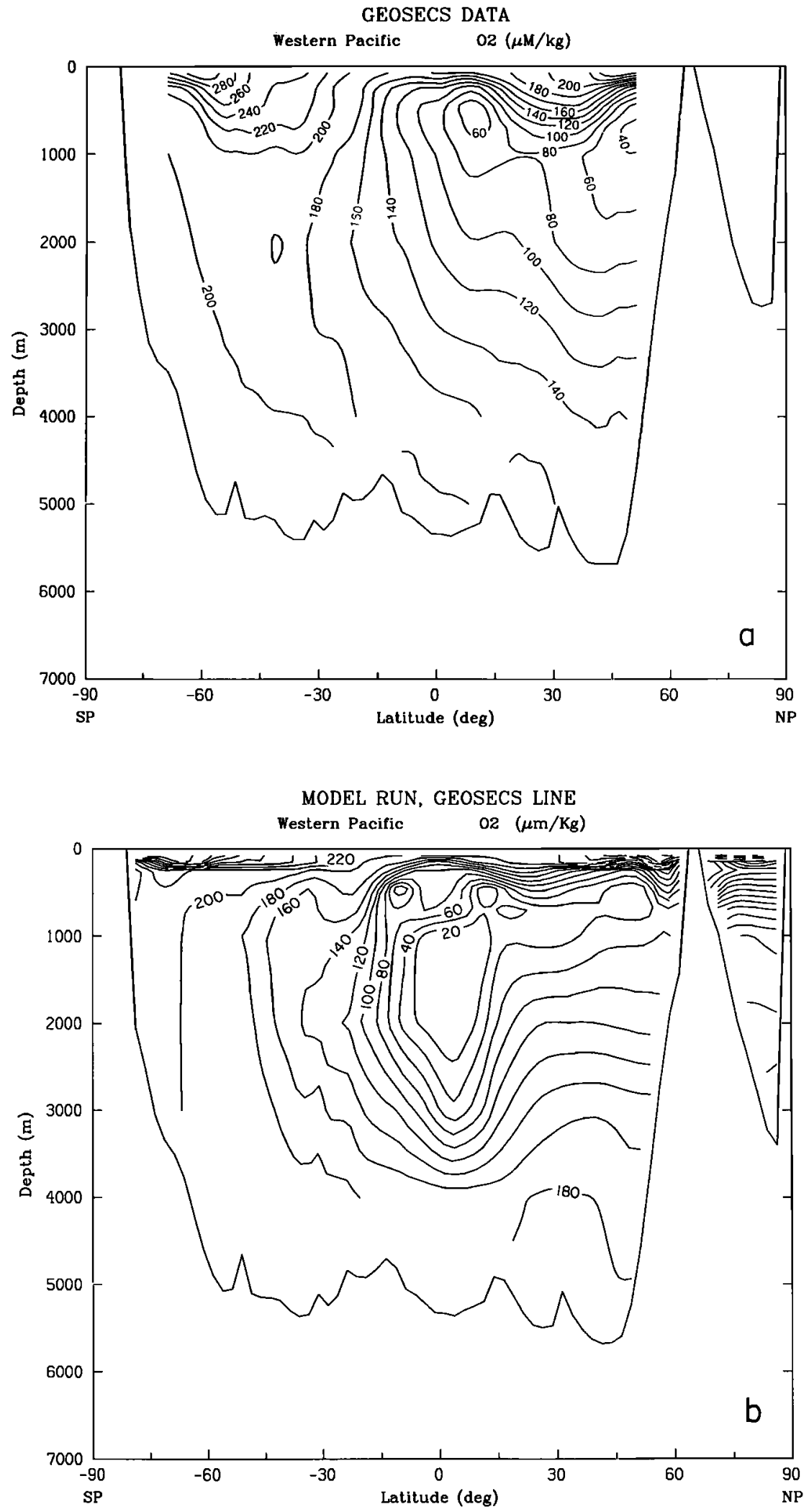

Fig. 6. Vertical sections of dissolved oxygen $\left(\mu \mathrm{mol} \mathrm{kg}^{-1}\right)$ in western Pacific Ocean: (a) GEOSECS data averaged over the resolution of the model, (b) prediction of model A, (c) prediction of model B, and (d) prediction of model C. 


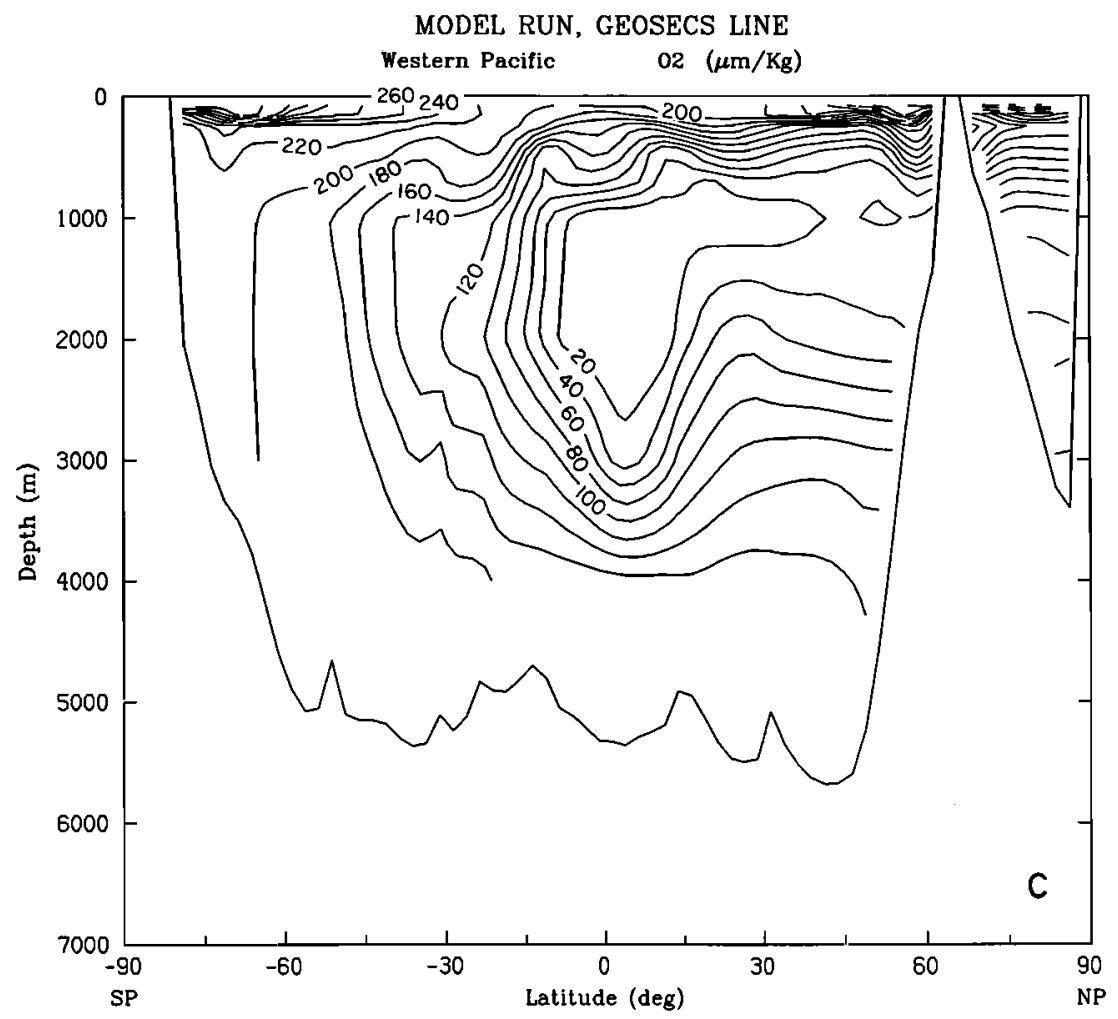

MODEL RUN, GEOSECS LINE

Western Pacific $\quad 02(\mu \mathrm{m} / \mathrm{Kg})$

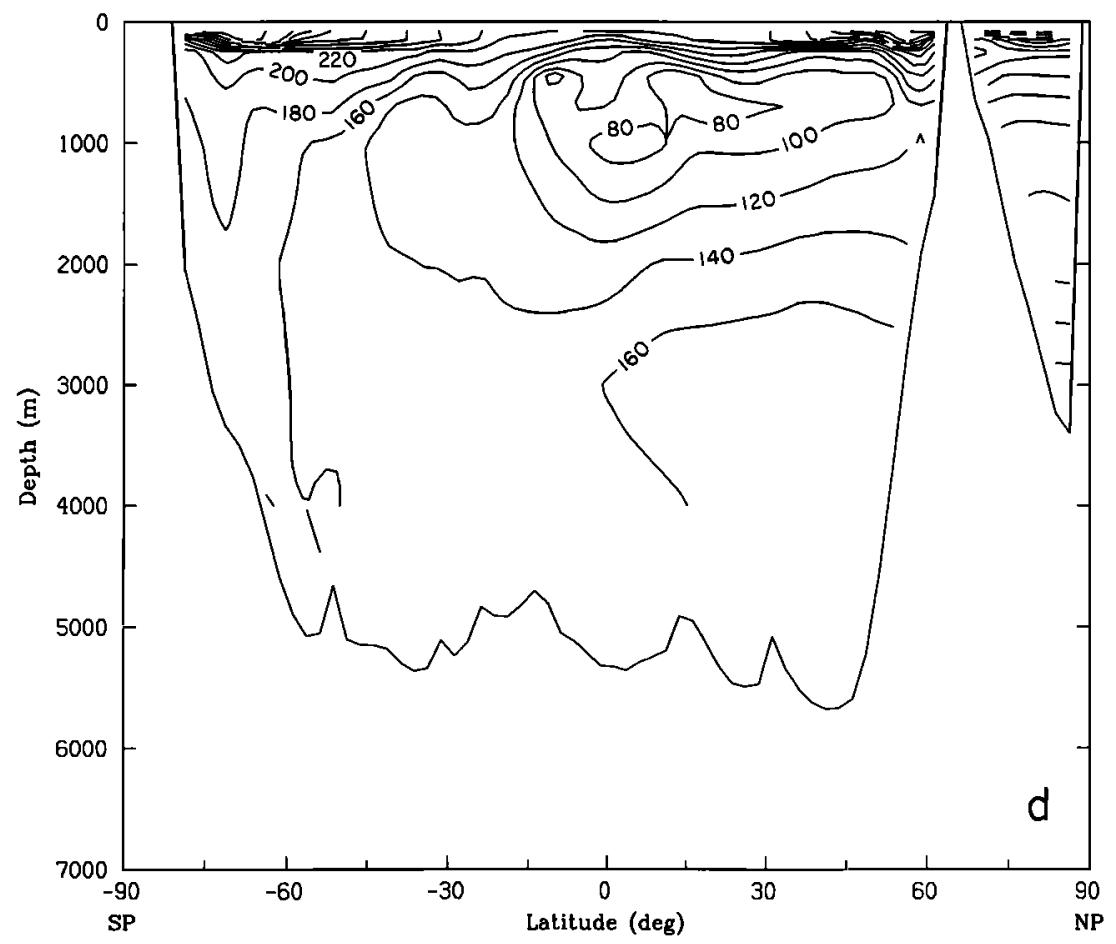

Fig. 6. (continued) 

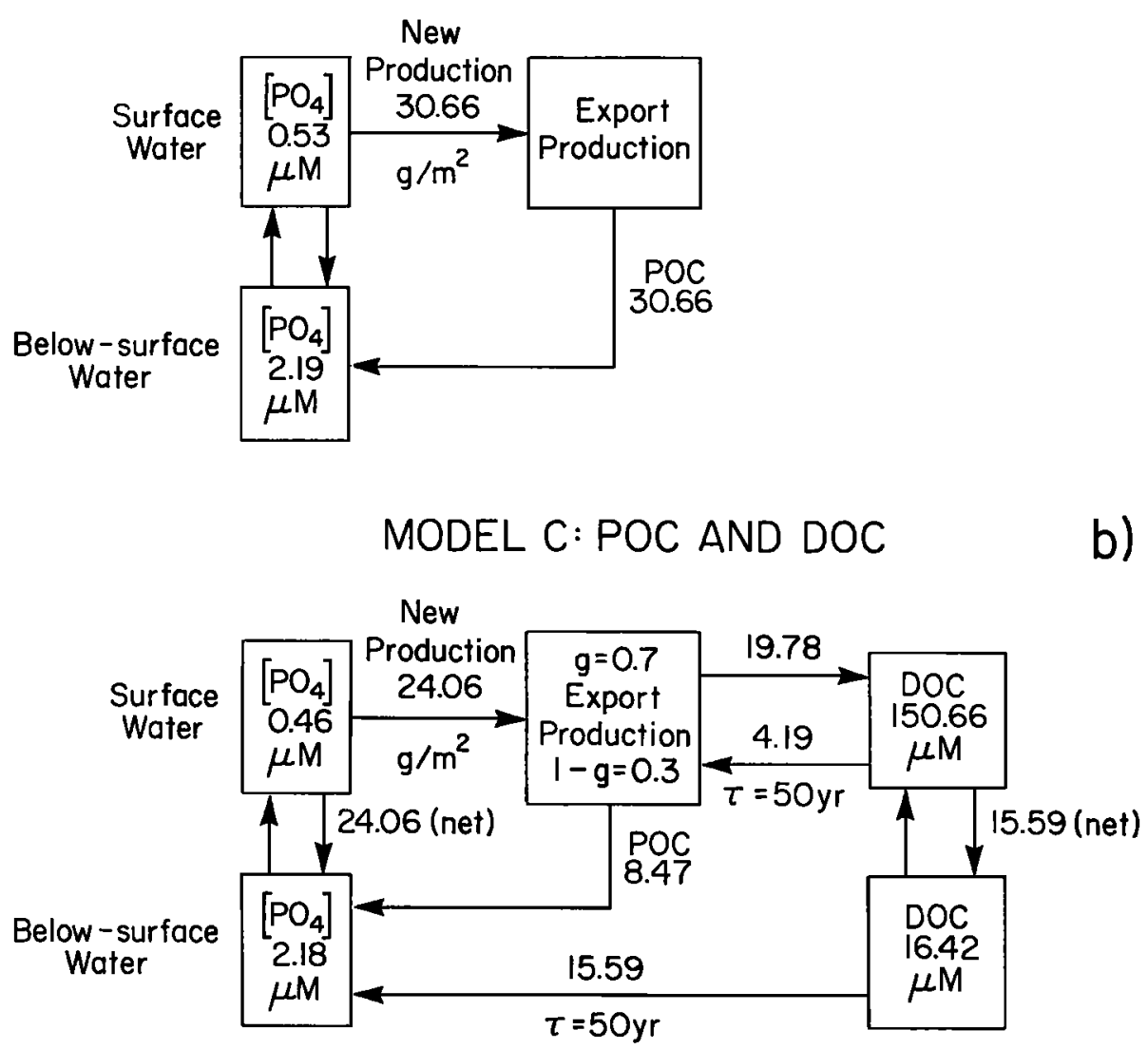

Fig. 7. Schematic illustration of new production models: (a) model A, POC only; and (b) model C, POC and DOC. Upper row of boxes represents averages over the surface boxes; lower row represents averages over the below-surface boxes. Fluxes $\left(\mathrm{g} \mathrm{C} \mathrm{m}^{-2} \mathrm{yr}^{-1}\right)$ are given above or to the right of an arrow or pair of arrows. POC refers to particulate organic carbon; DOC refers to dissolved organic carbon. For the model with DOC, $g=0.70$, so $70 \%$ of the export production flux is prescribed to go into DOC and the remainder goes into vertically falling POC. The time constant for consumption of DOC, $\tau$, is taken to be 50 years. The average new production flux of model $\mathrm{A}, 30.66 \mathrm{~g} \mathrm{C} \mathrm{m}^{-2} \mathrm{yr}^{-1}$, is equivalent to a flux of 22.12 $\mu \mathrm{mol} \mathrm{C} \mathrm{yr}{ }^{-1}$ from the surface boxes, or $10.80 \times 10^{15} \mathrm{~g} \mathrm{C} \mathrm{yr}^{-1}$, total, for all the oceans. The remineralization of the vertically falling POC has been specified by prescribing an exponential penetration depth of $300 \mathrm{~m}$ for both models.

average phosphate concentration is approximately 2.1 $\mu \mathrm{mol} \mathrm{kg} \mathrm{kg}^{-1}$ in all three models. About two thirds of the new production flux is carried by new DOC and one third by POC in model C (Figure 7b). The penetration depth of the POC in model C is set to $300 \mathrm{~m}$, the same as in model $A$. The conclusions above are not sensitive to the precise setting of these parameters, and we have not attempted to get the best possible agreement.

A reviewer of this manuscript has called our attention to the Ph.D. dissertation of R. G. Najjar [Najjar, 1990]. He has also used a carbon cycle model based on an oceanic GCM to compare models in which new production is transported by POC only with models in which new pro- duction is transported by DOC as well as POC and come to very similar conclusions.

\section{DOC-INDUCED PRODUCTION}

The return flux from new DOC in Figure $7 \mathrm{~b}$ into export production, $4.19 \mathrm{~g} \mathrm{C} \mathrm{m}^{-2} \mathrm{yr}^{-1}$, represents export production which is fueled by the release of nutrients in the consumption of new DOC. The associated primary production could be much larger and could perhaps explain observed production in the central North Pacific and other oligotrophic ocean regions. Hayward [1987] 


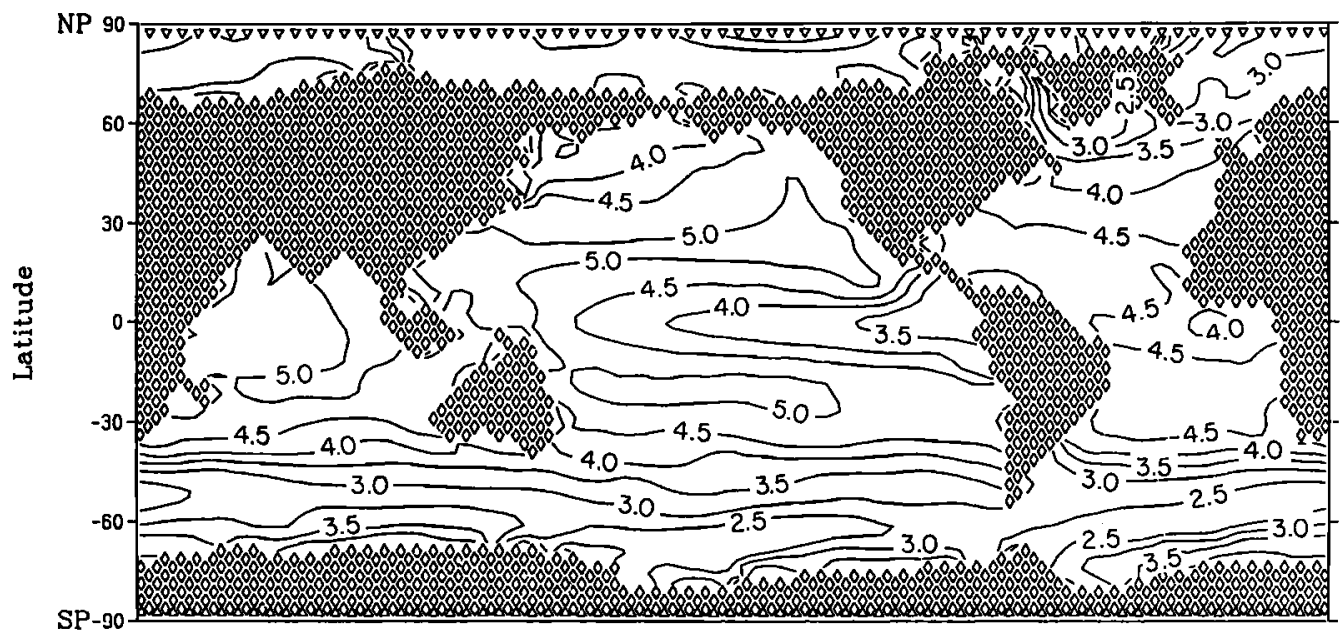

Longitude

Fig. 8. Export production due to recovery of nutrients from DOC in model C, illustrated in Figure 7b. This is just the DOC concentration divided by the lifetime, $\tau=50$ years, and converted to $\mathrm{g} \mathrm{C} \mathrm{m}^{-2} \mathrm{yr}^{-1}$.

has argued that in the central North Pacific, only a small part of the nutrient requirement can be explained by estimated eddy diffusivities and observed nutrient gradients. The nitrate concentration is near zero until well below the bottom of the euphotic layer, so eddy diffusive transport from below must occur across a near-zero gradient. Also, the top of the thermocline is above the nutricline for both summer and winter, and the nutricline depth does not change much between summer and winter, which argues against a model in which nutrients are brought up by the change with season of the mixed-layer depth.

The flux of export production from the relense of nutrients by DOC, with the lifetime of the DOC set to 50 years, is rather uniform over the surface of the ocean (Figure 8 ), and with $(1-g)=0.3,30 \%$ of this flux is prescribed to sink below the surface box of the model as POC. If this POC were caught in a moored particle trap experiment, the flux might be thought to represent new production in the region above the trap, but according to the definition of Dugdale and Goering [1967], the actual new production would have occurred at a distant location where the DOC was formed.

Acknowledgments. We wish to thank C. D. Keeling, T. Hayward, S. Piper, D. Collins, and C. O. Davis for useful suggestion and criticism. The work of R. Bacastow was supported by U.S. Department of Energy Carbon Research Division under subcontract 19X-43386C between Scripps Institution of Oceanography and Martin Marietta Energy Systems, Oak Ridge National Laboratory. Calculations were performed at the San Diego Supercomputer Center, which draws support from the U.S. National Science Foundation.

\section{REFERENCES}

Bacastow, R., and E. Maier-Reimer, Ocean-circulation model of the carbon cycle, Clim. Dyn., 4, 95-125, 1990.

Dugdale, R. C., Nutrient limitation in the sea: Dynamics, identification and significance, Limnol. Oceanogr., 12 685-695, 1967.

Dugdale, R. C., and J. J. Goering, Uptake of new and regenerated forms of nitrogen in primary productivity, Limnol. Oceanogr., 12, 196-206, 1967.

Eppley, R. W., and B. J. Peterson, Particulate organic matter flux and planktonic new production in the deep ocean, Nature, 282, 677-680, 1979.

Hayward, T. L., The nutrient distribution and primary production in the central North Pacific, Deep Sea Res., S4, 1593-1627, 1987.

Jackson, G., Implications of high dissolved organic matter concentrations for oceanic properties and processes, Oceanography, 1(2), 28-33, 1988.

Najjar, R. M., Simulations of the phosphorus and oxygen cycles in the world ocean using a general circulation model, Ph.D. dissertation, Princeton Univ., Princeton, N. J., 1990.

Martin, J. H., G. A. Knauer, D. M. Karl, and W. W. Broenkow, VERTEX: Carbon cycling in the northeast Pacific, Deep Sea Res., 34, 267-285, 1987.

Maier-Reimer, E., and K. Hasselmann, Transport and storage of $\mathrm{CO}_{2}$ in the ocean - An inorganic oceancirculation carbon cycle model, Clim. Dyn., 2, 63-90, 1987.

Peng, T.-H., and W. S. Broecker, $\mathrm{C}_{/} \mathbf{P}$ ratios in marine detritus, Global Biogeochem. Cycles, 1, 155-161, 1987.

Sarmiento, J. L., J. R. Toggweiler, and R. Najjar, Ocean 
carbon cycle dynamics and atmospheric $\mathrm{pCO}_{2}$, Philos. Trans. R. Soc. London, Ser. A, 925, 3-21, 1988.

Sugimura, Y., and Y. Suzuki, A high-temperature catalytic oxidation method for the determination of non-volatile dissolved organic carbon in seawater by direct injection of a liquid sample, Mar. Chem., 24, 105-131, 1988.

Suzuki, Y., Y. Sugimura, and T. Itoh, A catalytic oxidation method for the determination of total nitrogen dissolved in seawater, Mar. Chem., 16, 83-97, 1985.

Takahashi, T., W. S. Broecker, and S. Langer, Redfield ratio based on chemical data from isopycnal surfaces, J. Geophys. Res., 90, 6907-6924, 1985.

Toggweiler, J. R., Deep-sea carbon, A burning issue, Nature, 394, 468, 1988a.

Toggweiler, J. R., Is the downward dissolved organic matter flux important in carbon transport?, in Productivity of the Ocean: Present and Past (Dahlem Konferenzer), edited by W. H. Berger, V. S. Smetacek, and G. Wefer, pp. 65-83, John Wiley, New York, 1988b.
Williams, P. M., and E. R. M. Druffel, Radiocarbon in dissolved organic matter in the central North Pacific Ocean, Nature, s90, 246-248, 1987.

Williams, P. M., and E. R. M. Druffel, Dissolved organic matter in the oceans: Comments on a controversy, Oceanography, 1(1), 14-17, 1988.

R. Bacastow, Geological Research Division, A-020, Scripps Institution of Oceanography, University of California, San Diego, CA 92093.

E. Maier-Reimer, Max-Planck-Institut für Meteorologie, Bundesstrasse 55, Hamburg 13, Federal Republic of Germany.

(Received August 13, 1990; revised December 27, 1990; accepted December 27, 1990.) 